Article

\title{
Insulation Performance Comparison of Curtain Wall Systems with Existing Pipe Frames and Truss-Shaped Insulation Frames
}

\author{
Bo-Hye Choi and Seung-Yeong Song *(i) \\ Department of Architectural \& Urban Systems Engineering, Ewha Womans University, 52 Ewhayeodae-gil, \\ Seodaemun-gu, Seoul 03760, Korea; bhchoi@ewha.ac.kr \\ * Correspondence: archssy@ewha.ac.kr; Tel.: +82-2-3277-3913
}

Citation: Choi, B.-H.; Song, S.-Y. Insulation Performance Comparison of Curtain Wall Systems with Existing Pipe Frames and Truss-Shaped Insulation Frames. Energies 2021, 14, 4682. https://doi.org/10.3390/ en14154682

Academic Editors: Monica Siroux and Francesco Nocera

Received: 25 May 2021

Accepted: 26 July 2021

Published: 2 August 2021

Publisher's Note: MDPI stays neutral with regard to jurisdictional claims in published maps and institutional affiliations.

Copyright: (c) 2021 by the authors. Licensee MDPI, Basel, Switzerland. This article is an open access article distributed under the terms and conditions of the Creative Commons Attribution (CC BY) license (https:// creativecommons.org/licenses/by/ $4.0 /)$.

\begin{abstract}
The purpose of this study was to compare insulation performance between a base case that applied the existing steel pipe frame and an alternative case that reduced thermal bridging by applying a truss-shaped insulation frame (TIF) to a back frame type curtain wall. Insulation performance was compared by obtaining the effective U-factor and the lowest indoor surface temperature through a three-dimensional steady-state heat transfer simulation. In addition, mock-up tests were performed to compare the U-factors of the base case and alternative case. The simulation results showed that the effective U-factor of the alternative case was $36 \%$ lower than in the base case, a significant heat loss reduction. The lowest indoor surface temperature of the alternative case was $0.5^{\circ} \mathrm{C}$ higher than in the base case, showing that the surface condensation risk also decreased. In the mock-up test results, the alternative case U-factor was 33\% lower than in the base case, confirming the associated large heat loss reduction. For the base case, both the effective U-factor by simulation and the U-factor by the mock-up test were much higher than the design U-factor according to the Korean Design Standard, which neglects thermal bridging, indicating a significantly increased heat loss caused by this factor. For the alternative case, however, both U-factors were similar to the design U-factor.
\end{abstract}

Keywords: thermal insulation; thermal bridge; curtain wall; truss-shaped insulation frame

\section{Introduction}

\subsection{Background and Objective}

Reducing greenhouse gas (GHG) emissions is a global issue, and the international community has made efforts to reduce GHG emissions at the global level. The Paris Agreement signed in 2015 dealt with measures to reduce GHG emissions after 2020, and the South Korean government also established and announced the "Revision of the basic roadmap for achieving the national greenhouse gas reduction target in 2030 [1]" by reflecting the Paris Agreement. In the case of the building sector, which represents 22\% of GHG emissions from South Korea as of 2017, a reduction target of $32.7 \%$ compared to the expected GHG emissions by 2030 was set. In addition, the reinforcement of building permit standards for new buildings, improvement of the energy performance of the existing buildings, improvement of equipment efficiency, and expansion of the distribution of renewable energy systems were presented as the main measures to reduce GHG emissions. Accordingly, zero energy building certification has become mandatory for new public buildings with a total floor area of $1000 \mathrm{~m}^{2}$ or larger since 2020 , and the certification will be mandatory for all new buildings with a total floor area of $500 \mathrm{~m}^{2}$ or larger after 2030 [2].

Thermal insulation of the building envelope is a very important element for zero energy buildings. The building envelope that requires thermal insulation can be mainly classified into the external wall, roof and floor. Since the external wall generally represents the largest area in buildings, the insulation performance of the external wall is particularly important. Even though there are some differences depending on the construction method, most external walls have thermal bridges in which insulation is partially discontinued. The 
thermal bridge becomes a path through which heat is transferred between the indoor and outdoor space, thereby reducing insulation performance and causing many problems, such as energy loss and condensation. In the case of the curtain wall, in particular, the risk of thermal bridge occurrence is higher than that of the concrete wall, because metal materials with high thermal conductivity are applied and many joints are inevitably required between various components [3]. Therefore, although the curtain wall satisfies the design U-factor (assuming one-dimensional heat transfer and not considering the influence of the thermal bridge) required by the Design Standard for Energy-Efficient Buildings [4], its actual U-factor is highly likely to be larger than the design U-factor.

The back frame type curtain wall, in which exterior finish materials are installed after the installation of grid-type or straight-type frames on the building structure as shown in Figure $1[5,6]$, has been widely applied as external walls in various types of buildings due to its simple installation and low cost. In general, frames are made of painted or galvanized rectangular steel pipes and fixed to the building structure using fasteners (primary connectors). Exterior finish materials such as metal or stone are fixed to the frames using brackets (secondary connectors). Insulation is installed between frames (see Figure 1c) or between the frame and exterior finish material.

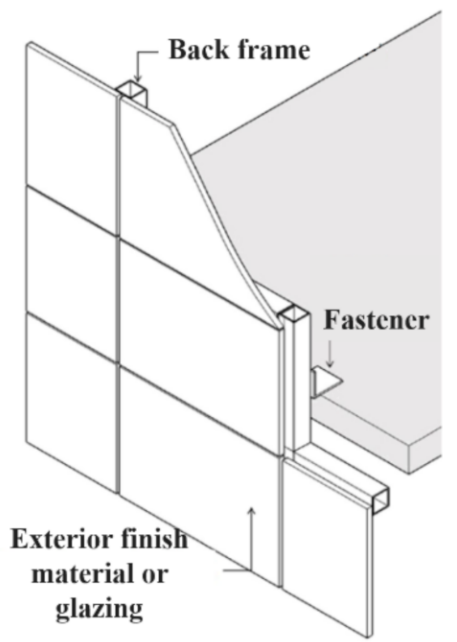

(a)

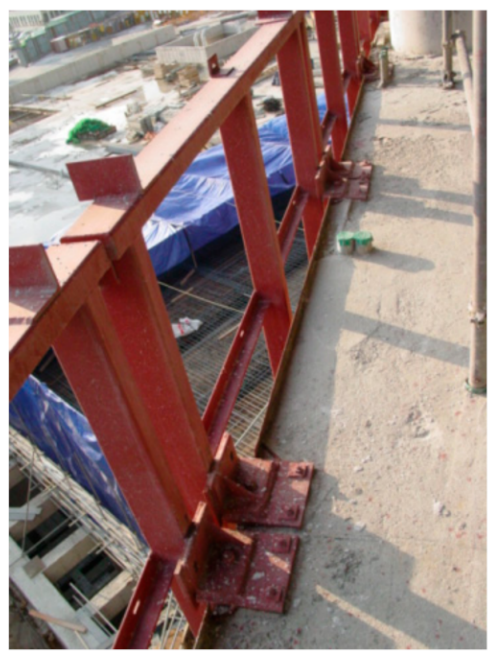

(b)

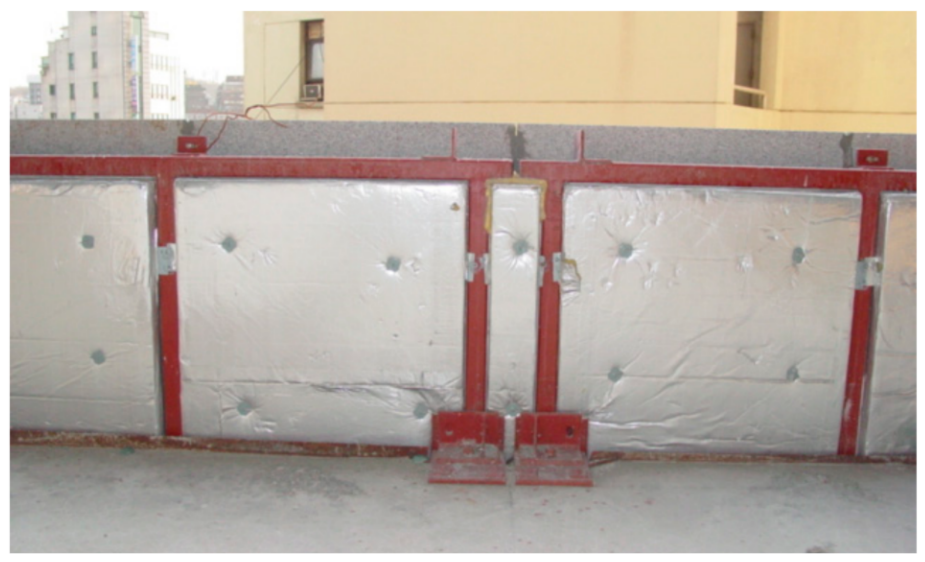

(c)

Figure 1. Configuration and example of back frame type curtain wall: (a) configuration [5,6]; (b) example of a back frame; (c) example of insulation installation.

Kim, S.-S. et al. [7] reported that the insulation performance of metal materials with high thermal conductivity is a major element that determines the insulation performance of 
the entire curtain wall as the insulation performance of the vision parts, such as windows, in the curtain wall is reinforced. Song, J.-H. et al. [8] divided the back frame type curtain wall into panel type and sheet type walls depending on the exterior finish materials and insulation installation method, and evaluated the insulation performance of each type. They reported that the joints between metal panels and the secondary connectors act as thermal bridges for the panel type, in which metal panels containing insulation are fixed to frames, and the frames themselves also become thermal bridges for the sheet type, in which metal sheets are fixed to frames and insulation is installed between frames. Brent Griffith et al. [9] evaluated the thermal performance of a curtain wall through experiments and simulation by varying the spacing and material of bolts. They reported that the spacing of bolts affected the thermal performance of the curtain wall, and that the thermal performance was reduced when the spacing was narrow or steel bolts were used instead of stainless-steel bolts. Park, H.-Y. et al. [10] evaluated the impacts of major materials on the U-factor of the curtain wall. They compared the U-factor between the case in which the influence of screws that played a structural role was included and the case in which the influence was excluded, and reported that the thermal bridge must be considered first to improve the insulation performance of the curtain wall. Theodoros G. et al. [11] analyzed the effect of fasteners that are used to fix exterior materials and insulation on the insulation performance of external wall, and reported that measures to reduce the thermal bridge are required. Oh, J.-M. et al. [12] replaced aluminum molding on the side of metal panels that are used as exterior materials in the curtain wall with plastic molding, and reported that the insertion of a thermal breaker into the existing aluminum bracket significantly decreases the thermal bridging effect at joints between panels.

As in the research results above, metal materials that are installed in the insulation layer in the curtain wall are highly likely to become thermal bridges. The steel pipe frame installed in the back frame type curtain wall as shown in Figure 1c also becomes a thermal bridge that penetrates the insulation layer, and it becomes a major factor that reduces the insulation performance of the entire curtain wall. To resolve this problem, Shin, D.-I. [13] proposed a truss-shaped insulation frame (TIF) composed of galvanized steel plates, stainless steel wires, and insulation, and analyzed the improvement effect of insulation performance (refer to Section 2 for details on TIF). Later, Song, J.-H. et al. [14,15] tested the structural deflection and movement, air leakage, water penetration, fire resistance and thermal resistance for the external wall system to which the TIF proposed by Shin, D.-I. [13] was applied, and reported that it satisfied the performance criteria required by building codes and improved insulation performance through a reduction in the thermal bridging effect. In this study, a three-dimensional heat transfer analysis model of $1 \mathrm{~m}$ in size was set up to calculate the heating and cooling energy demand, and the linear thermal transmittance of the thermal bridge on the vertical member was calculated.

It appears that the TIF has high potential for improving insulation performance by reducing the thermal bridging effect when applied to the back frame type curtain wall. Its application range is expected to be wide as it is also applicable to exterior insulation and finish systems of concrete walls and new construction as well as remodeling. Since the TIF system is in the early stages of application, its performance evaluation, verification and sufficient data are required under various building conditions. Therefore, in this study, insulation performance was compared between cases that applied the existing steel pipe frame and TIF, by reflecting the actual module dimensions and members of the back frame type curtain wall for office buildings. For an overall insulation performance comparison of the entire curtain wall system, the effective U-factor that integrates the effects of linear and point thermal bridge elements was derived, and the improvements on insulation performance through application of TIF was analyzed and verified. 


\subsection{Methods and Procedures}

An investigation into the TIF, which was developed to reduce the thermal bridging effect caused by the existing steel pipe frame, was performed. Using Physibel Trisco software, three-dimensional steady-state heat transfer simulations were performed to compare the insulation performance between the base case that applied the steel pipe frame and the alternative case that applied the TIF. The module dimensions applied to actual office buildings were applied, and modeling was performed including thermal bridge elements such as vertical and horizontal frames and metal fasteners. Windows were excluded from the modeling range because separate frames are installed and there is no significant difference between the base case and alternative case. The insulation performance of the alternative case was compared with that of the base case based on the heat loss through the entire analysis area and the resulting effective U-factor as well as the lowest indoor surface temperature and the resulting temperature difference ratio (TDR). In addition, mock-ups of the base case and alternative case were manufactured for the same analysis area, and the U-factor test was conducted in accordance with Korean Standard (KS) F 2278 [16] to verify the insulation performance of the alternative case. Figure 2 shows the methodological outline of this study.

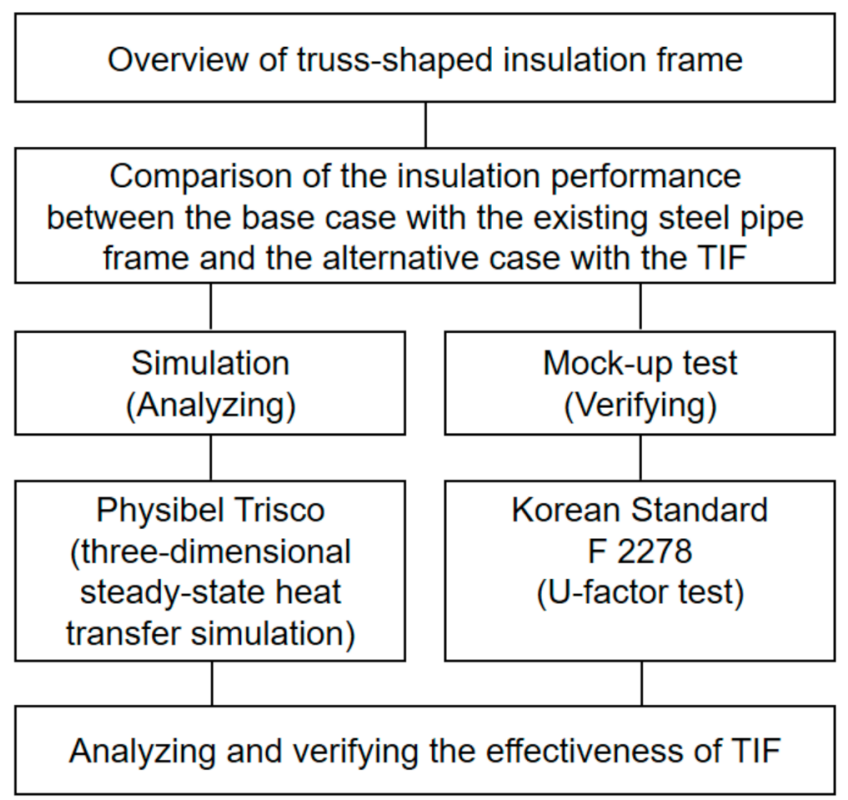

Figure 2. Methodology outline of the study.

\section{Overview of Truss-Shaped Insulation Frame}

The TIF was developed to reduce the thermal bridging effect caused by the vertical frame that acts as the structural frame for fixing exterior finish materials in curtain wall systems or exterior insulation and finish systems of concrete walls [13]. As shown in Figure 3, the TIF consists of top and bottom plates which are manufactured by processing galvanized steel plates, stainless steel wires that connect the top and bottom plates in a truss shape, and insulation that fills the empty space inside frames. The top plate has a t-bolt hole, and the bottom plate has bolt holes. This makes it easy to fix the frame to the building structure and exterior materials to the frame, and enables dry construction without additional welding. Inside the frame, inorganic insulation is filled to secure fire resistance and insulation performance. Since insulation is installed continuously, as shown in Figure $4 \mathrm{~b}$, it is possible to reduce the thermal bridging effect that inevitably occurs when the existing steel pipe frame is applied. 


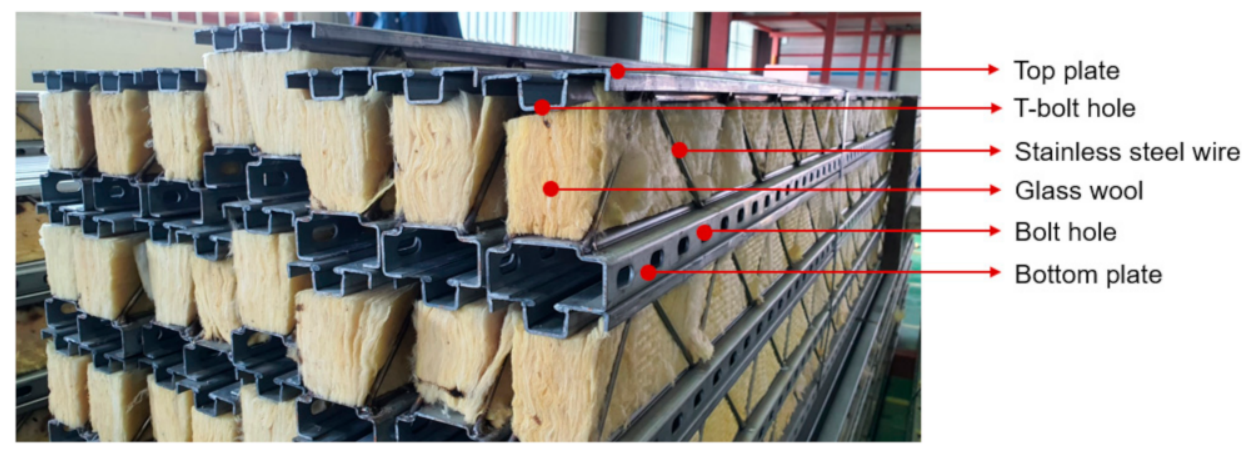

Figure 3. Configuration of the truss-shaped insulation frame (TIF).

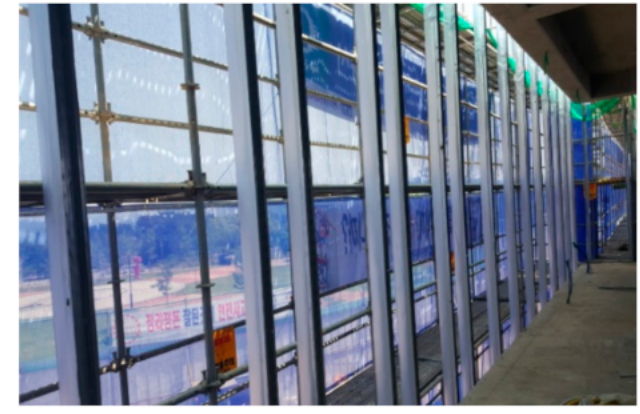

(a)

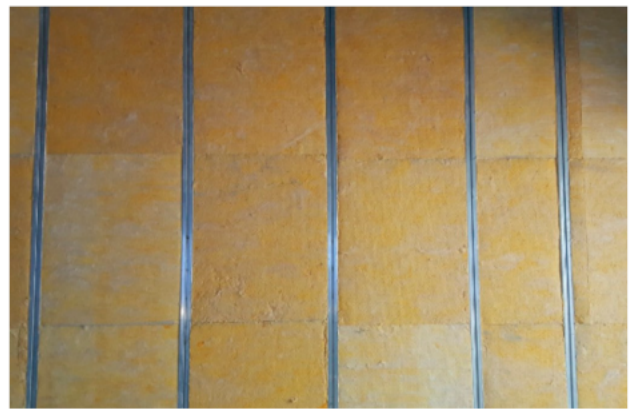

(b)

Figure 4. Installation example of the TIF and insulation: (a) installation of the TIF; (b) installation of insulation between the TIFs.

\section{Setup of the Base Case and Alternative Case}

The building type was set to an office building for which there are many cases of applying curtain wall systems, and the exterior finish material was set to the commonly used aluminum sheet. Recently, in Korea, the fire safety standards [17] have been strengthened significantly, and non-flammable building materials are strongly recommended for buildings with three or more floors. Accordingly, glass wool, which provides fire resistance and insulation performance, was applied to the TIF. In addition, mineral wool was installed in the interlayer fire partition between the insulation and floor slab based on the actual design drawing. The design U-factor (U-factor in the Design Standard that assumes one-dimensional heat transfer and does not consider the thermal bridging effect) of the curtain wall system was set to less than $0.150 \mathrm{~W} / \mathrm{m}^{2} \mathrm{~K}$, which is the required U-factor for Seoul determined by the Design Standard [4]. Seoul corresponds to zone 4 in the climate zone classification of ASHRAE Standard 90.1 [18]. The design U-factor that reflected the actual thickness of each component of the curtain wall system was $0.145 \mathrm{~W} / \mathrm{m}^{2} \mathrm{~K}$.

For the base case, rectangular steel pipe frames with cross-sectional dimensions of $125 \mathrm{~mm} \times 75 \mathrm{~mm}$ and $100 \mathrm{~mm} \times 50 \mathrm{~mm}$ are installed vertically and horizontally, respectively, and two layers of glass wool with a total thickness of $220 \mathrm{~mm}$ are inserted between frames. On the outdoor side of the frame, a rectangular steel pipe track with cross-sectional dimensions of $50 \mathrm{~mm} \times 50 \mathrm{~mm}$ is installed to fix the exterior finish material, and the aluminum sheet with a thickness of $4 \mathrm{~mm}$ is installed for an exterior finish material. There are air cavities between the gypsum board (an interior finish material) and the glass wool, and between the aluminum sheet (an exterior finish material) and the glass wool.

For the alternative case, the interior and exterior finish materials, as well as the track for fixing the exterior material, are the same as those of the base case, and TIFs of the same size $(125 \mathrm{~mm} \times 75 \mathrm{~mm})$ are installed at $1 \mathrm{~m}$ intervals instead of vertical rectangular steel pipe frames. As in the base case, two layers of glass wool with a total thickness of $220 \mathrm{~mm}$ are installed between TIFs. On the indoor side of the TIFs, an L-shaped stainless-steel track 
is installed horizontally. The L-shaped stainless-steel track supports insulation as with the horizontal rectangular steel pipe frame of the base case. Since the L-shaped stainlesssteel track can be a thermal bridge as it is connected to the TIFs and installed inside the insulation layer, a T-shaped polyamide insulation cap is applied to one end of the L-shaped stainless-steel track, as shown in Figure 5.

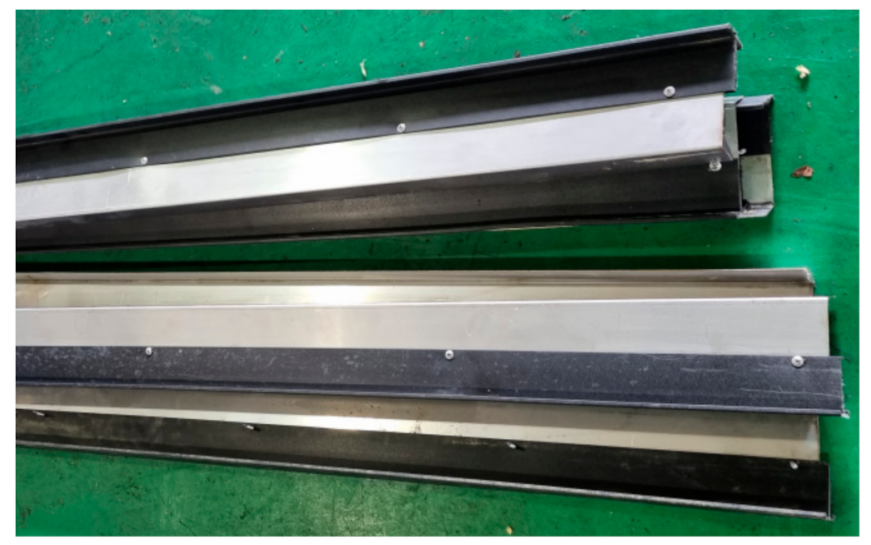

Figure 5. L-shaped stainless-steel track with polyamide T-cap.

\section{Three-Dimensional Steady-State Heat Transfer Simulation}

\subsection{Overview of Simulation}

\subsubsection{Simulation Model}

The simulation area is the non-vision parts of the curtain wall system, and it was modeled in three dimensions, including the plenum, ceiling, and floor slab to which the frame is fixed. In the curtain wall system, detailed conditions, such as spacing of vertical and horizontal frame and the location of metal fasteners, may vary depending on the building situation, but conditions that are generally applied to office buildings were used in this study. All elements that can be thermal bridges, such as frames and metal fasteners, were included for modeling, and thin membranes with negligible influence on heat transfer, such as vapor barriers, were excluded from modeling in accordance with ISO 10211 [19].

In three-dimensional modeling the location of cut-off planes was set by referring to ISO 10211 [19], and the location of cut-off planes in the $x$-axis direction was set to be the middle point between the vertical frames as shown in Figure 6. The location of cut-off planes in the $y$-axis direction was set to be the point at least $1 \mathrm{~m}$ from the interior finishing surface of the wall. The location of cut-off planes in the $z$-axis direction was set to the middle point of the aluminum sheet, which was at least $1 \mathrm{~m}$ from the finishing surface of the floor and the ceiling.

The three-dimensional models of the base case and alternative case modeled through the above process had the same size $(1000 \mathrm{~mm}, 1850 \mathrm{~mm}$, and $4000 \mathrm{~mm}$ in the $x-, y-$, and $z$-axis directions, respectively). In addition, the two models had the same outdoor and indoor surface areas so that the evaluation results could be compared. Figures 7 and 8 show the horizontal and vertical sections of the base case and alternative case. Figure 9 shows the three-dimensional geometric models of the base case and alternative case. 


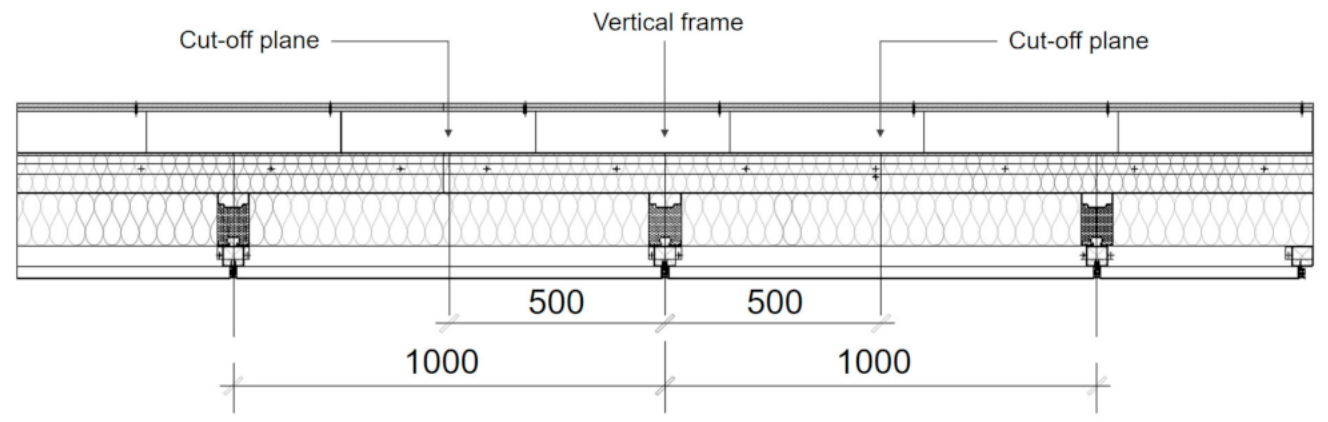

Figure 6. Location of cut-off planes for simulation.

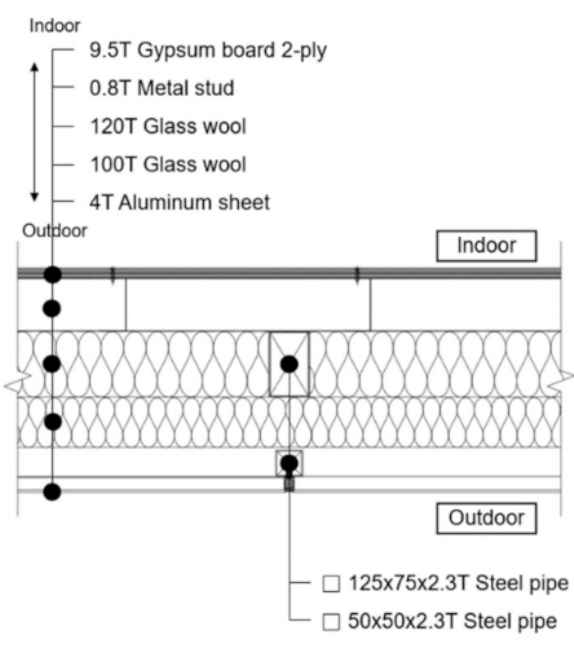

(a)

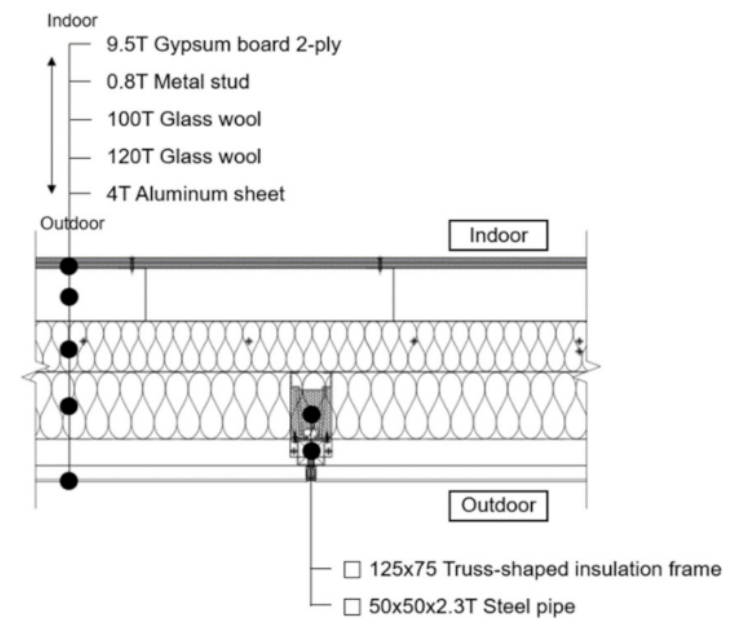

(b)

Figure 7. Horizontal sections of the simulation models: (a) base case; (b) alternative case.

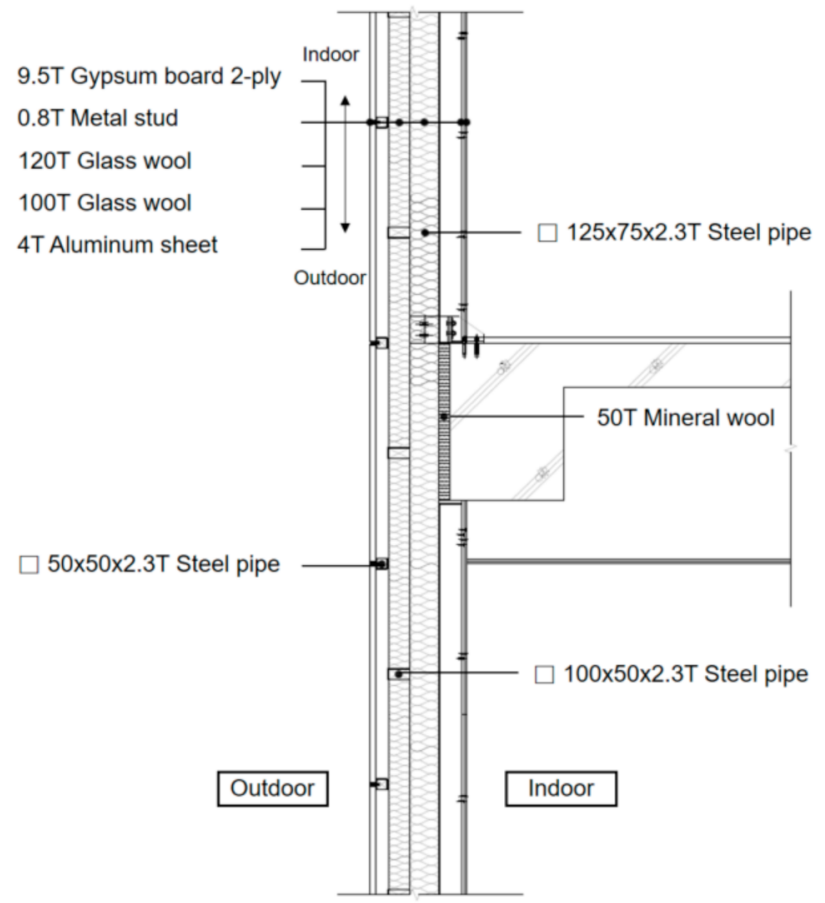

(a)

Figure 8. Cont. 


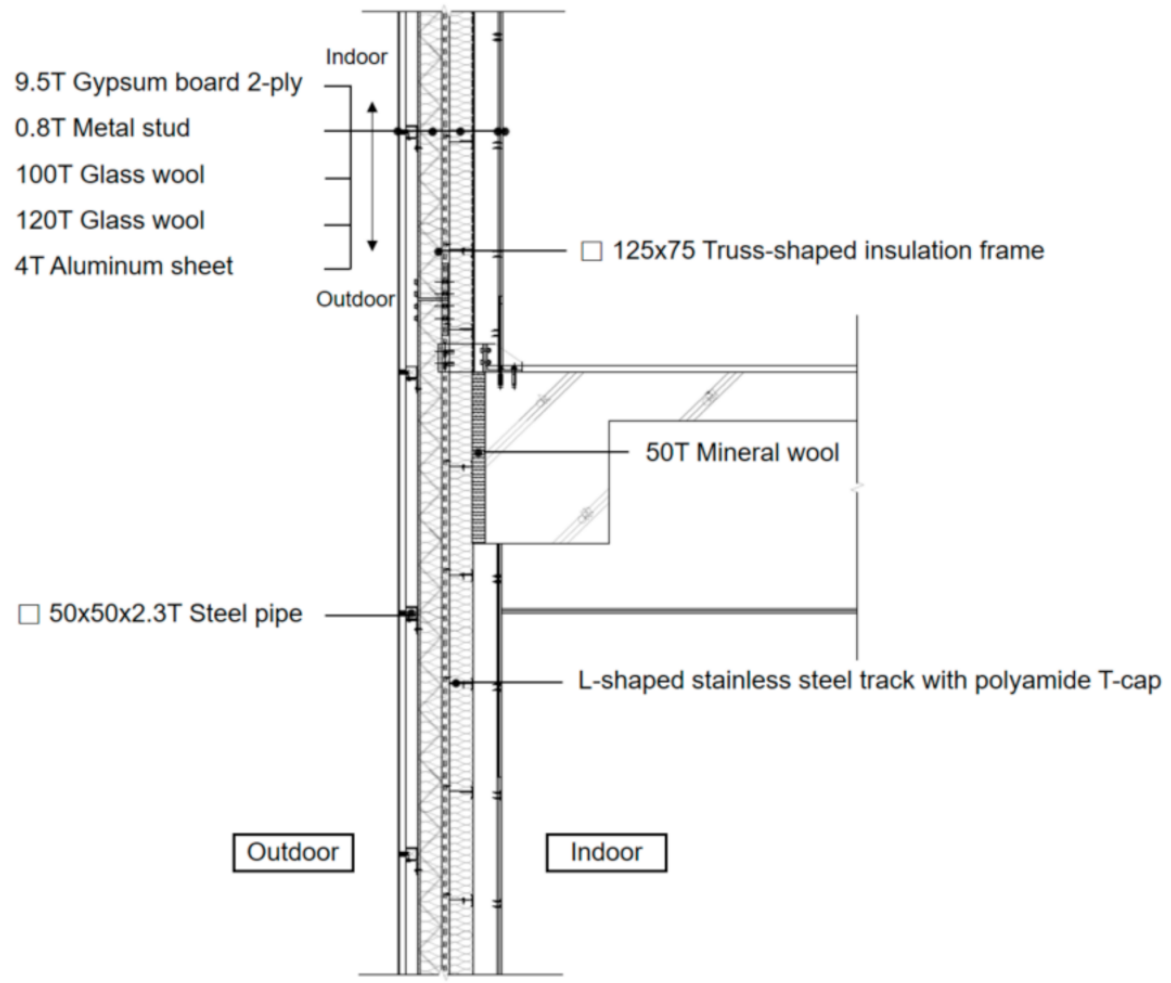

(b)

Figure 8. Vertical sections of the simulation models: (a) base case; (b) alternative case.

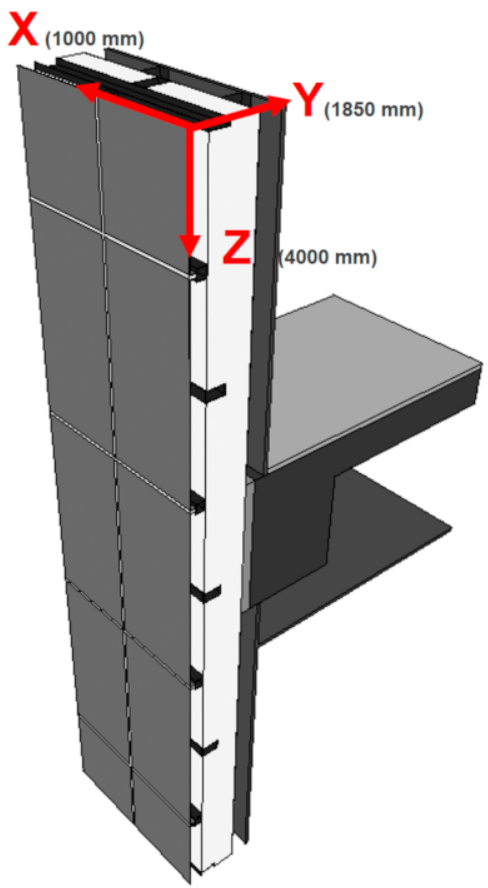

(a)

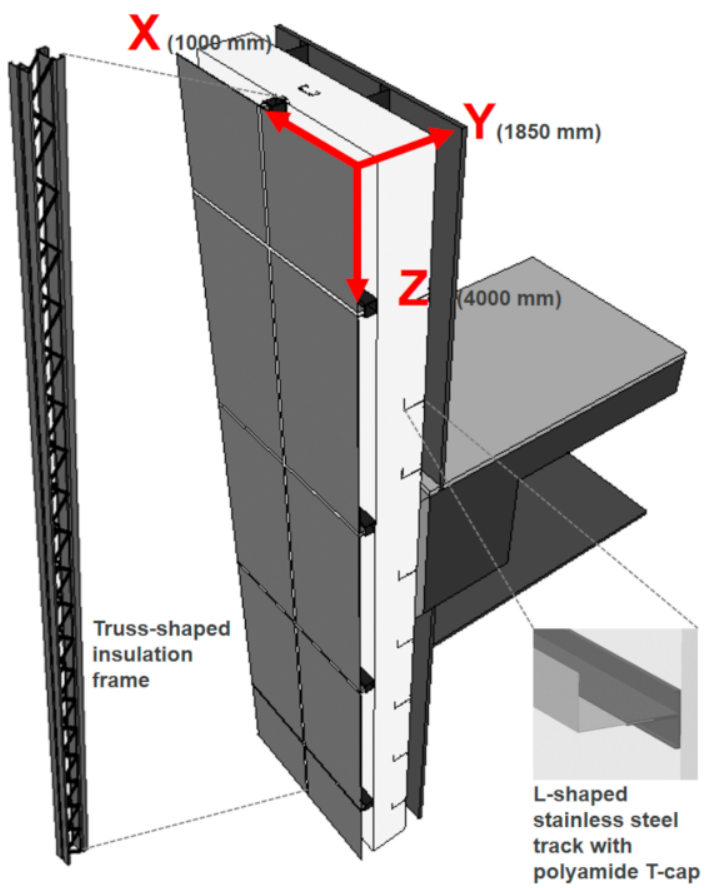

(b)

Figure 9. Three-dimensional geometric models in Physibel Trisco: (a) base case; (b) alternative case. 


\subsubsection{Simulation Method}

The insulation performance of the base and alternative cases was evaluated through three-dimensional steady-state heat transfer simulation. Physibel Trisco $14.0 \mathrm{w}$ was used as the heat transfer simulation software. Physibel Trisco is commercial and multi-purpose heat transfer simulation software made by Physibel, which enables calculations precisely for the complex building elements [20].

In the heat transfer simulation, boundary conditions were applied in accordance with the Design Standard for Energy-Efficient Buildings [4] and material properties in accordance with the Guide to Design Standard for Energy-Efficient Buildings [21] and ISO 10077-2 [22]. The outdoor temperature in the boundary conditions is the design outdoor temperature of Seoul for heating equipment capacity calculation. The heat transfer in the air cavity was calculated using the equivalent thermal conductivity, which was obtained according to the convective and radiative heat transfer coefficients, air cavity geometry, and heat flow direction. Tables 1 and 2 show the boundary conditions and material properties for the simulation, respectively.

Table 1. Boundary conditions for simulation.

\begin{tabular}{ccc}
\hline Boundary & Temperature $\left({ }^{\circ} \mathbf{C}\right)$ & Surface Heat Transfer Coefficient $\left(\mathbf{W} / \mathbf{m}^{2} \mathbf{K}\right)$ \\
\hline Outdoor & -11.3 & 23.26 \\
Indoor & 20 & 9.09 \\
\hline
\end{tabular}

Table 2. Material properties for simulation.

\begin{tabular}{cccc}
\hline Material & $\begin{array}{c}\text { Thermal Conductivity } \\
(\mathbf{W} / \mathbf{m K})\end{array}$ & Material & $\begin{array}{c}\text { Thermal Conductivity } \\
\text { (W/mK) }\end{array}$ \\
\hline Concrete & 1.6 & Steel & 44 \\
Cement mortar & 1.4 & Galvanized steel & 53 \\
Gypsum board & 0.18 & Stainless steel & 15 \\
Glass wool & 0.034 & Polyamide & 0.25 \\
Mineral wool & 0.036 & Silicone sealant & 0.35 \\
Aluminum sheet & 200 & - & - \\
\hline
\end{tabular}

\subsubsection{Evaluation Indices of Insulation Performance}

The insulation performance of the alternative case was compared with that of the base case based on the heat loss through the entire analysis area and the resulting effective U-factor as well as the lowest indoor surface temperature and the resulting TDR. Equations (1) and (2) represent calculation formulas for the effective U-factor and TDR, respectively. TDR is the condensation prevention performance index determined by the Design Standard for Preventing Condensation [23] in South Korea. A lower TDR value is more favorable for preventing surface condensation, and the value is obtained by rounding down the third decimal place.

$$
\mathrm{Ueff}=\frac{q}{A \times(T i-T o)}
$$

where $\mathrm{U}_{\text {eff }}$ : effective $\mathrm{U}$-factor $\left(\mathrm{W} / \mathrm{m}^{2} \mathrm{~K}\right), q$ : heat loss $(\mathrm{W}), A$ : outdoor surface area $\left(\mathrm{m}^{2}\right), T_{i}$ : indoor temperature $(\mathrm{K}), T_{0}$ : outdoor temperature $(\mathrm{K})$.

$$
\mathrm{TDR}=\frac{T i-T s i}{T i-T o}
$$

where $T_{i}$ : indoor temperature $\left({ }^{\circ} \mathrm{C}\right), T_{s i}$ : indoor surface temperature $\left({ }^{\circ} \mathrm{C}\right), T_{0}$ : outdoor temperature $\left({ }^{\circ} \mathrm{C}\right)$. 


\subsection{Simulation Results}

Table 3 shows the evaluation results of insulation performance of the base case and alternative case by simulation. For the base case in which the rectangular steel pipe frame was applied, the heat loss was $33.1 \mathrm{~W}$ and the resulting effective U-factor was found to be $0.264 \mathrm{~W} / \mathrm{m}^{2} \mathrm{~K}$. For the alternative case that applied TIF, however, the heat loss was $21.1 \mathrm{~W}$ and the resulting effective $\mathrm{U}$-factor was reduced by $36 \%$ compared to the base case as it was $0.169 \mathrm{~W} / \mathrm{m}^{2} \mathrm{~K}$, indicating a significant reduction in heat loss by decreasing the thermal bridging effect.

Table 3. Evaluation results of insulation performance by simulation.

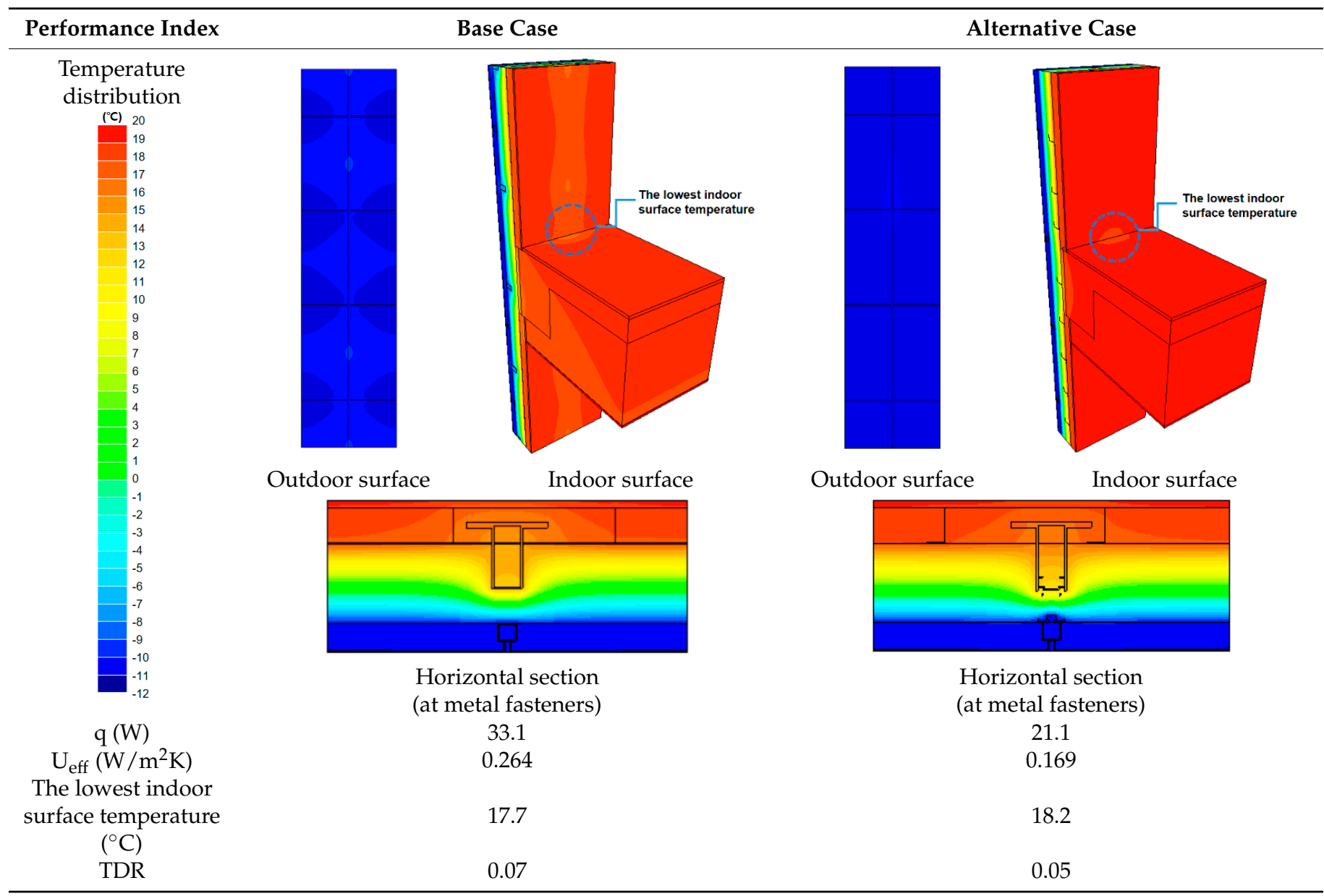

For the base case, the lowest indoor surface temperature was $17.7^{\circ} \mathrm{C}$, and the resulting TDR was 0.07 . For the alternative case, the lowest indoor surface temperature was $18.2^{\circ} \mathrm{C}$, which was $0.5{ }^{\circ} \mathrm{C}$ higher than that of the base case, and the resulting TDR was 0.05 , indicating that the surface condensation risk was also reduced. The lowest indoor surface temperature occurred on the surface adjacent to the fastener installed to fix the vertical member to the structure for both the base and alternative case. This is due to the drop in surface temperature in neighboring areas around the metal fasteners.

\section{Performance Verification through Mock-Up Test}

\subsection{Overview of Mock-Up Test}

\subsubsection{Mock-Up Model}

For the U-factor test of the base case and alternative case, mock-ups were manufactured for the same analysis area as the simulation. The U-factor test method for curtain wall systems is dealt with in KS F 2278 [16]. The size of the test specimens specified in 
KS F 2278 is $2 \mathrm{~m} \times 2 \mathrm{~m}$. Accordingly, mock-ups were manufactured by including two vertical and horizontal frames, as well as the vertical and horizontal midpoints of the aluminum sheet, an exterior finishing material, as shown in Figures 10-12. The maximum thickness of the insulation panel surrounding the test specimen (see Figure 11) installed in a government-certified testing laboratory (Korea Laboratory Accreditation Scheme) in South Korea is $400 \mathrm{~mm}$, and the maximum allowed thickness of the test specimens is $350 \mathrm{~mm}$. Since the thickness of the curtain wall in simulation models was $419 \mathrm{~mm}$, mock-ups were manufactured by excluding the air cavity ( $100 \mathrm{~mm}$ thick) between the gypsum board and glass wool as well as the metal stud installed inside the air cavity for fixing the gypsum board. Owing to the constraints of the test method specified by KS F 2278, the floor structures and primary connectors included in the simulation models were excluded for the mock-ups. Mock-ups were prepared by including thin membranes that were excluded from the simulation models, such as vapor retarders. Except for these, the configuration of the mock-ups was the same as that of the simulation models. Figures 11 and 12 show the horizontal and vertical sections of the mock-ups for the base case and alternative case.

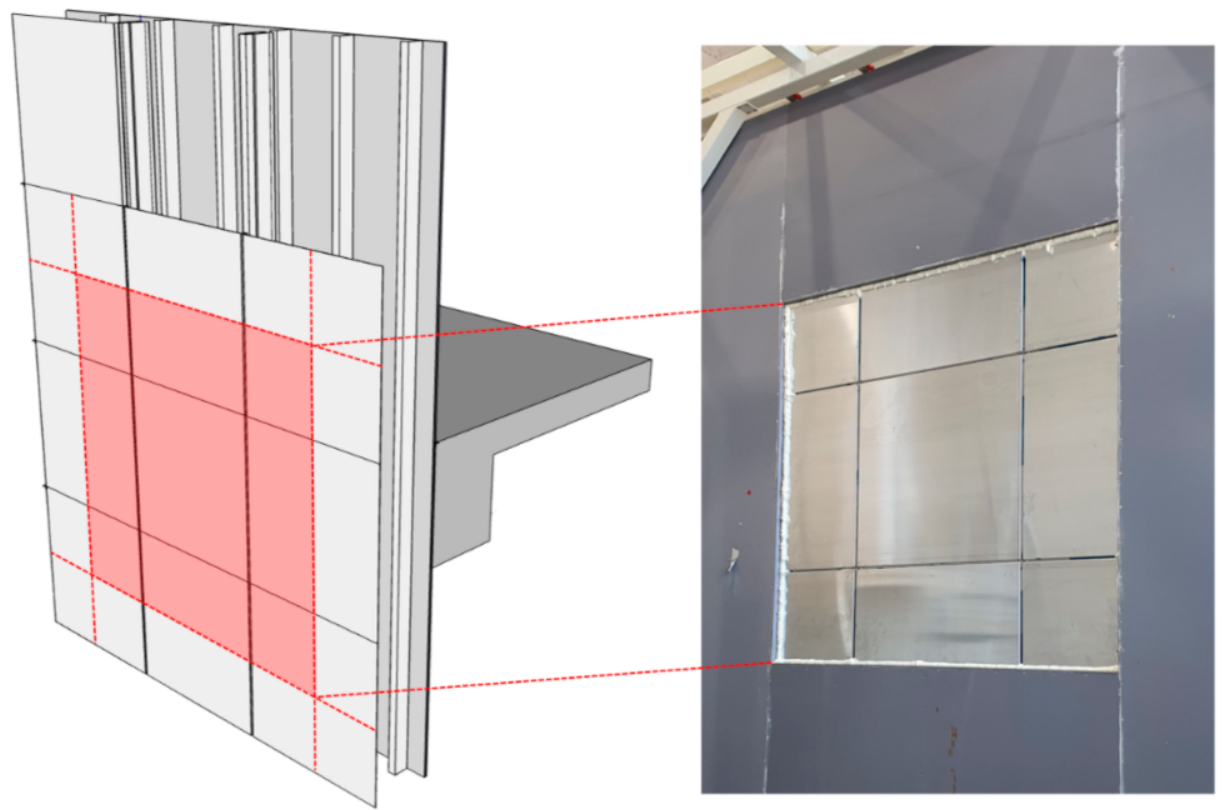

Figure 10. Location of cut-off planes for mock-up test.

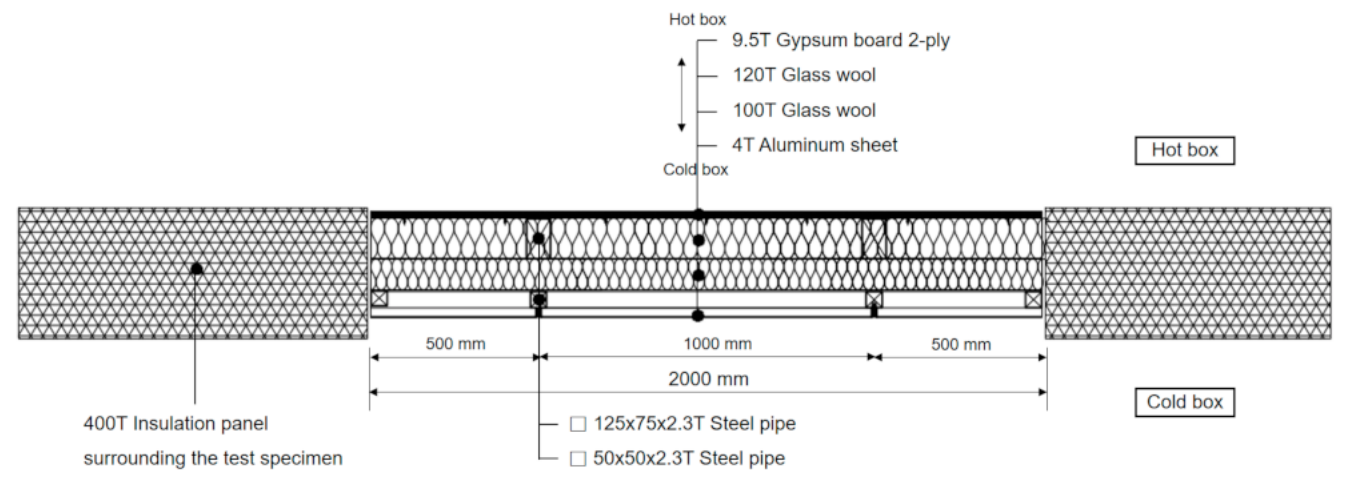

(a)

Figure 11. Cont. 


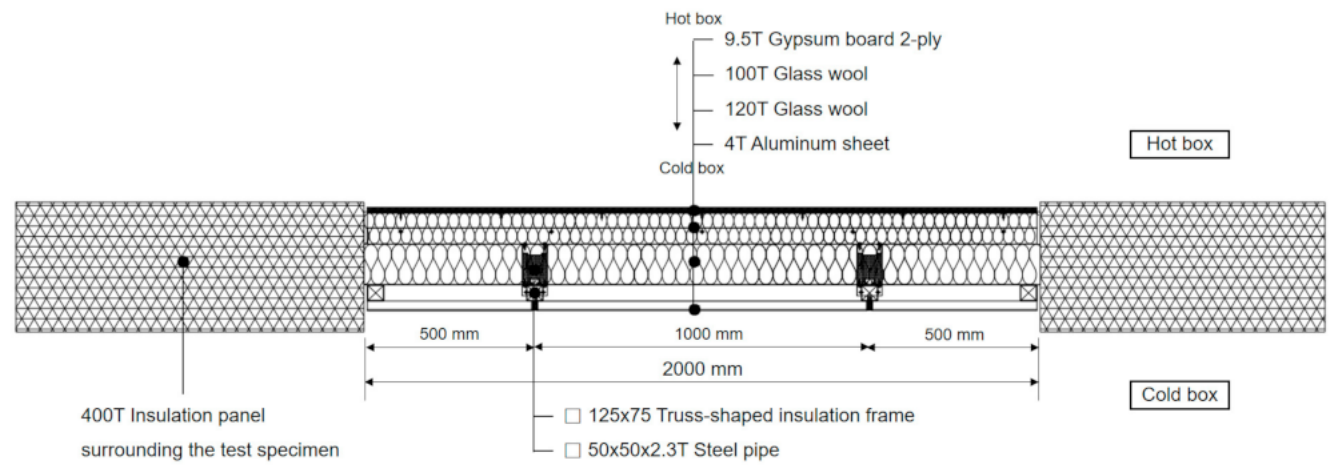

(b)

Figure 11. Horizontal sections of mock-ups: (a) base case; (b) alternative case.

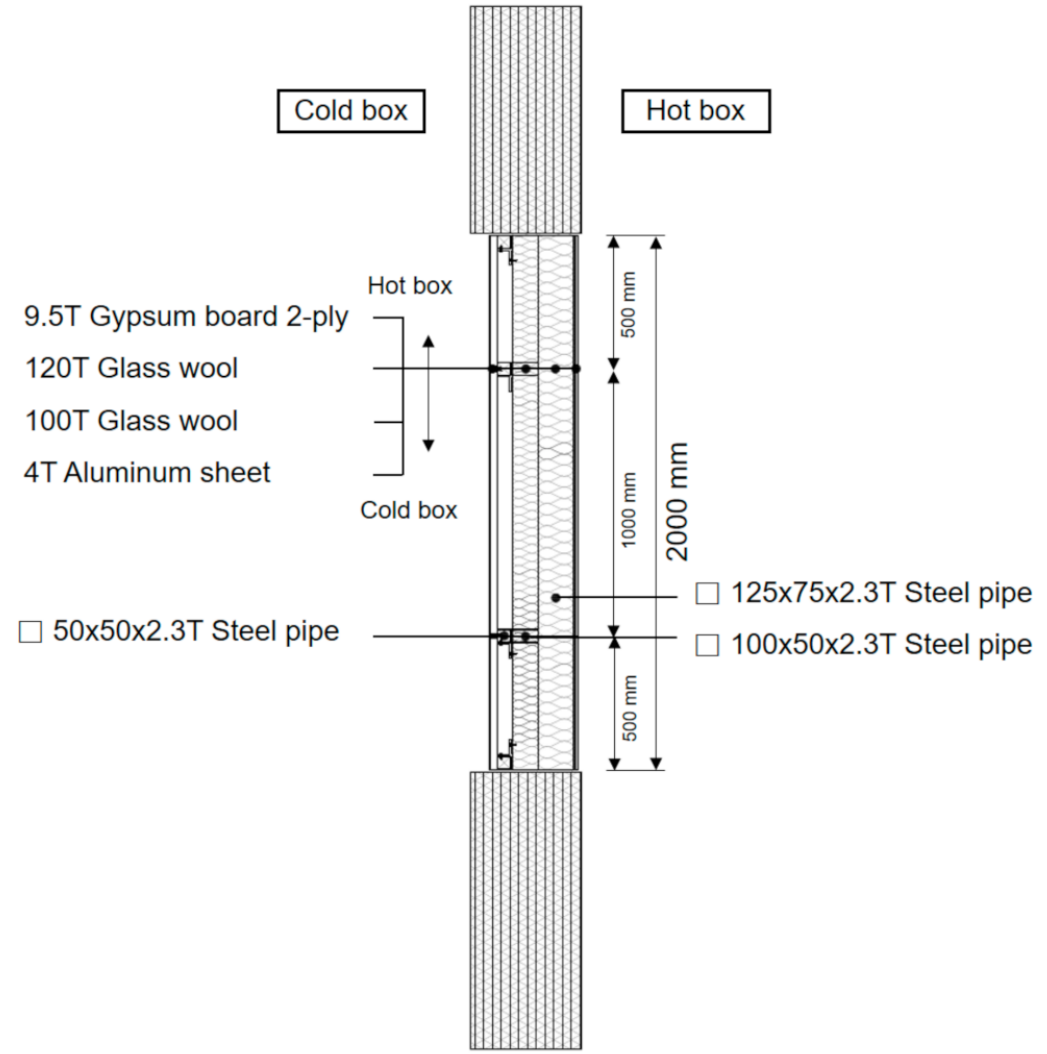

(a)

Figure 12. Cont. 


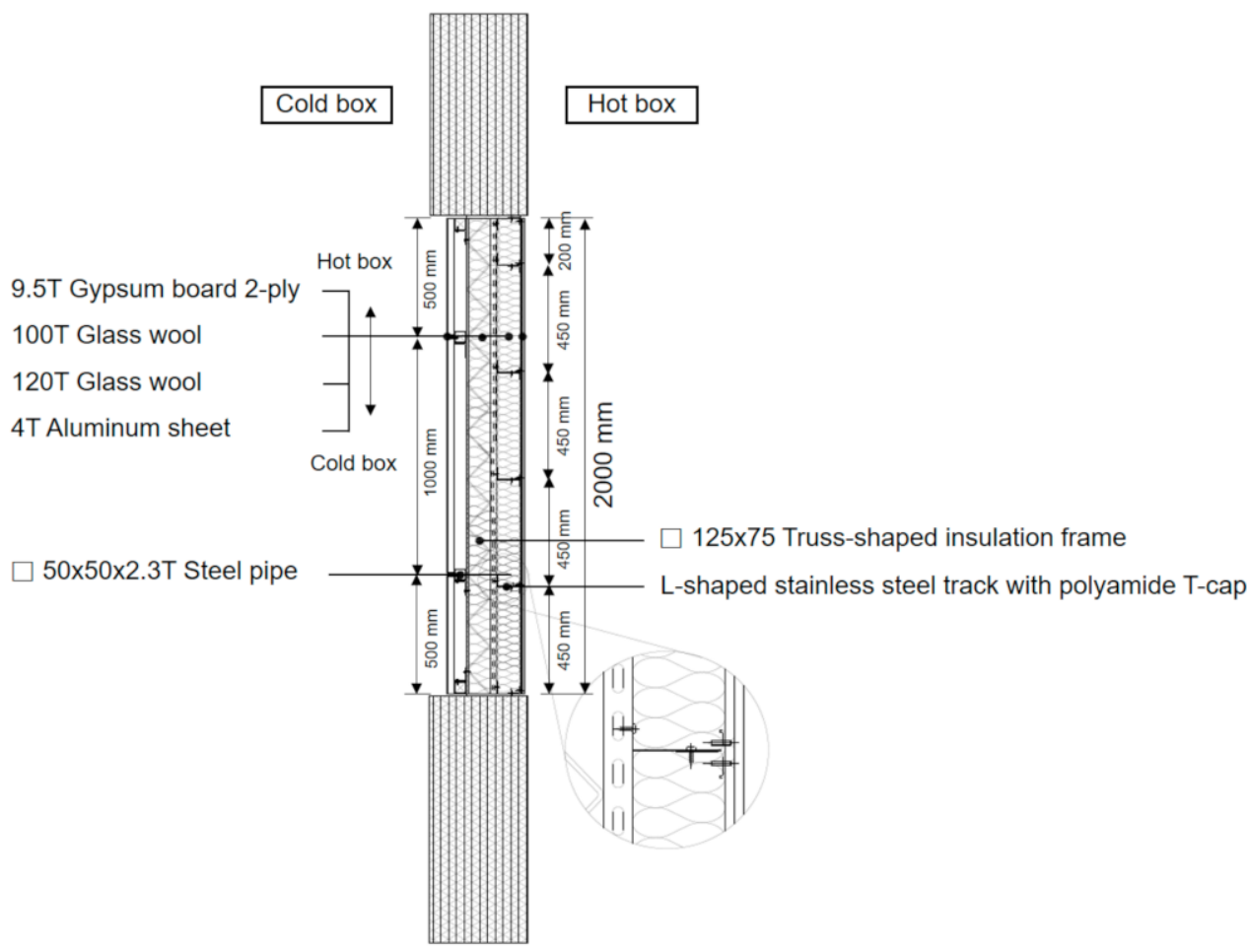

(b)

Figure 12. Vertical sections of mock-ups: (a) base case; (b) alternative case.

\subsubsection{Mock-Up Test Method}

The U-factor test device consists of a cold box corresponding to the outdoor environment and a hot box corresponding to the indoor environment. There is an insulation panel into which a test specimen is inserted between the cold and hot boxes, and the hot box is located inside the constant temperature chamber. Figure 13 shows the mock-ups installed for the U-factor test. The gap between the insulation panel and each mock-up was filled with polyurethane foam.

In KS F 2278, the surface thermal resistance is first set by measuring the air temperature in the cold box and hot box and the surface temperature (see Figure 14) of the standard insulation board installed in place of the test specimen under steady-state conditions, and then the U-factor of the test specimen is obtained by measuring the air temperature in the cold box, hot box, and constant temperature chamber as well as the amounts of heat supplied to the cold and hot boxes under steady-state conditions. The U-factor test for the base case and alternative case was conducted in a government-certified testing laboratory in South Korea. Table 4 shows the boundary conditions applied to the cold and hot boxes.

Table 4. Boundary conditions for mock-up test.

\begin{tabular}{ccc}
\hline Boundary & Temperature $\left({ }^{\circ} \mathbf{C}\right)$ & Surface Thermal Resistance $\left(\mathbf{m}^{2} \mathbf{K} / \mathbf{W}\right)$ \\
\hline Cold box & $0 \pm 1.0$ & $0.05 \pm 0.02$ \\
Hot box & $20.0 \pm 1.0$ & $0.11 \pm 0.02$ \\
\hline
\end{tabular}




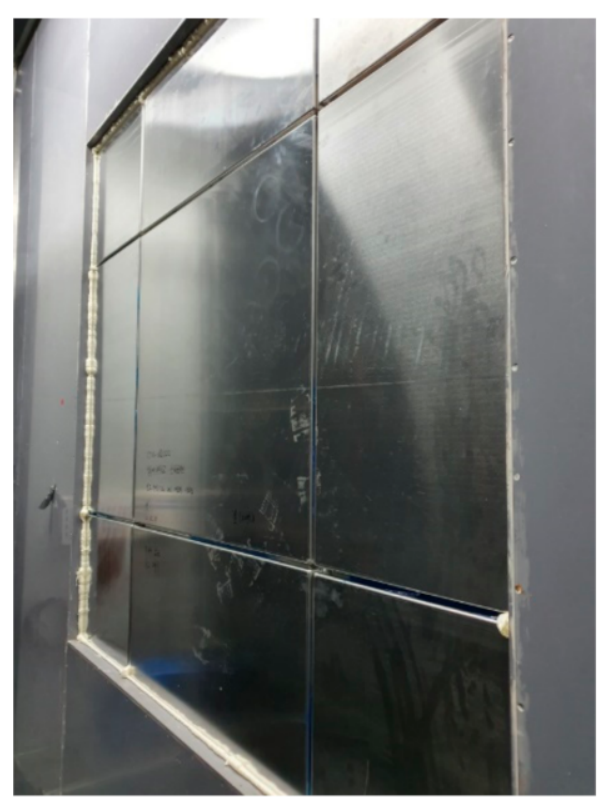

(a)

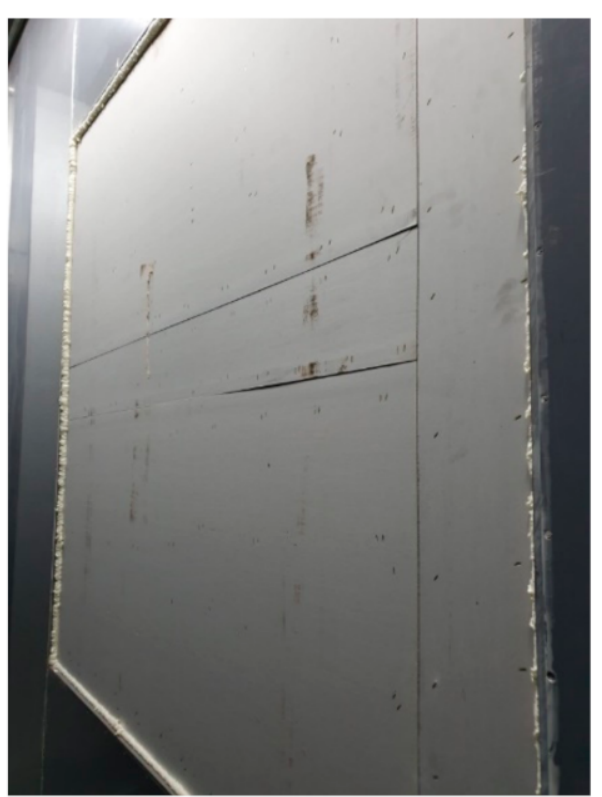

(b)

Figure 13. Installation of mock-up: (a) cold box side; (b) hot box side.

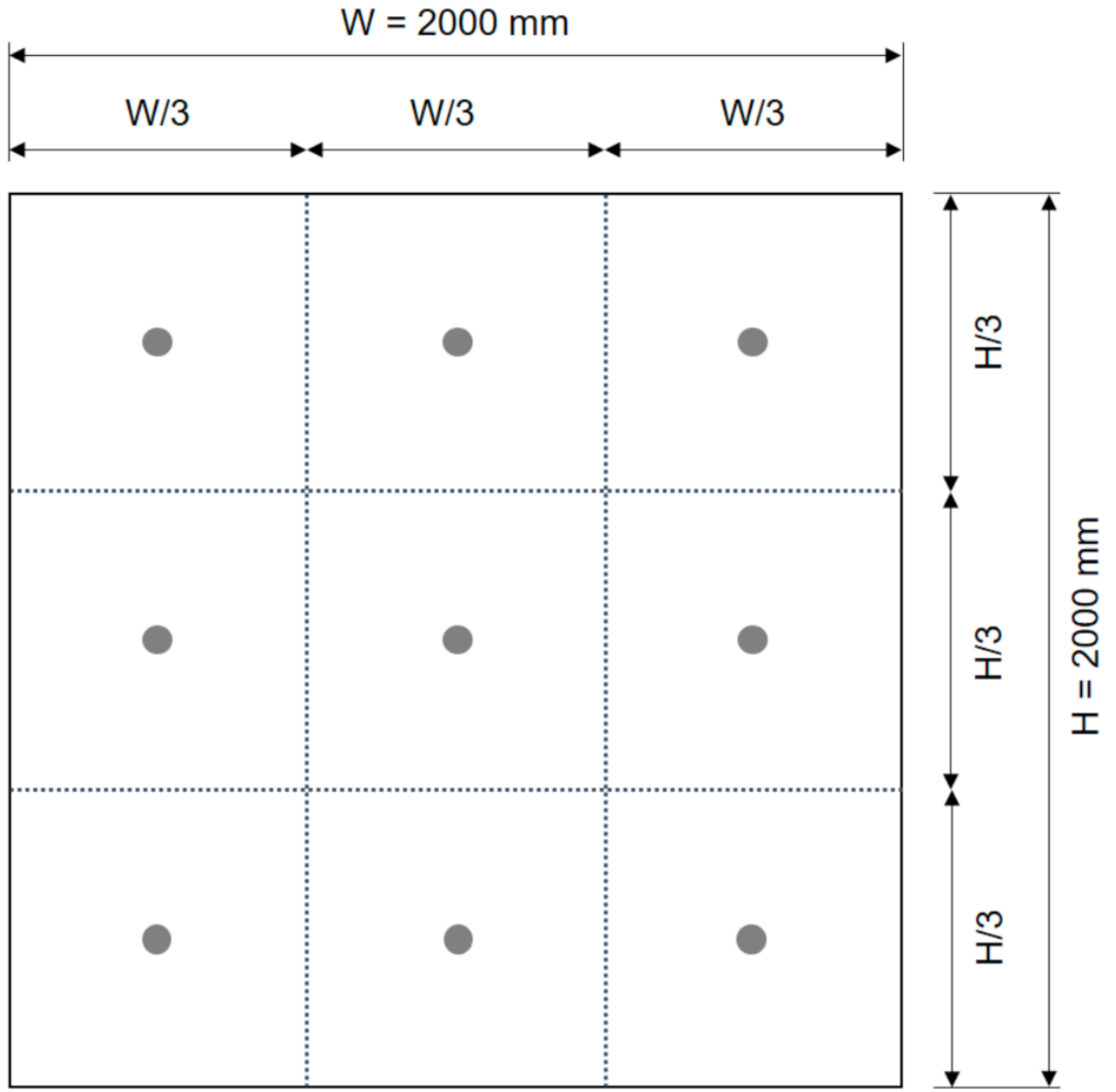

Figure 14. Surface temperature measurement points on the cold box and hot box side to pre-set the surface thermal resistance. 


\subsection{Mock-Up Test Results}

The U-factor by the mock-up test was found to be $0.220 \mathrm{~W} / \mathrm{m}^{2} \mathrm{~K}$ for the base case and $0.147 \mathrm{~W} / \mathrm{m}^{2} \mathrm{~K}$ for the alternative case. Similar to the effective U-factor reduction level in the simulation results, the U-factor of the alternative case was reduced by $33 \%$ compared to that of the base case, confirming the significant heat loss reduction effect of the alternative case.

For both the base case and alternative case, the U-factor by the mock-up test was found to be slightly lower than the effective U-factor by simulation. This result can be attributed to some differences in configuration between the simulation models and mock-ups (refer to Section 5.1.1). The effective U-factor reduction degree of the alternative case compared to the base case in the simulation results; however, it was almost the same as the U-factor reduction degree in the mock-up test results.

Figure 15 shows the effective U-factors by simulation, U-factors by the mock-up test, and design U-factors according to the Design Standard [4], which does not consider the influence of the thermal bridge under the assumption of one-dimensional heat transfer, for the base case and alternative case. For the base case, both the effective U-factor by simulation and the U-factor by the mock-up test were much higher than the design Ufactor of $0.145 \mathrm{~W} / \mathrm{m}^{2} \mathrm{~K}$, indicating a significant increase in heat loss due to the thermal bridge. This is similar to the results of Song, J.-H. et al. [14,15], which tested for insulation performance of the TIF-applied external wall system. Although it was designed as a Ufactor that satisfies the Design Standard, the actual insulation performance in terms of the effective U-factor considering the thermal bridges were found to be much weaker. So, it is necessary to improve and supplement the current Design Standard so that the effect of thermal bridges can be reflected. For the alternative case, however, both were found to be similar to the design U-factor.

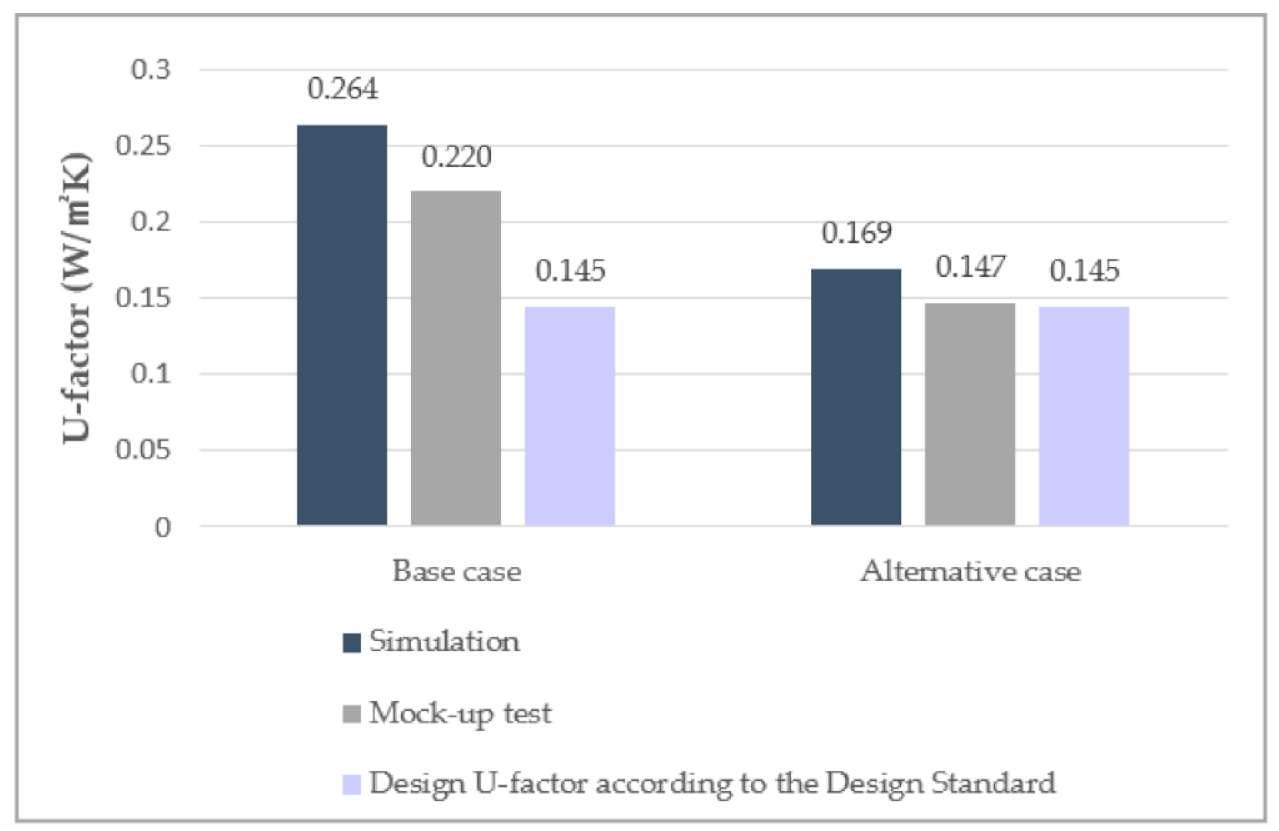

Figure 15. U-factor evaluation results.

\section{Conclusions}

The purpose of this study is to compare insulation performance between the base case, which applied the rectangular steel pipe frame, and the alternative case, which reduced the thermal bridging effect by applying the truss-shaped insulation frame (TIF), by reflecting the actual module dimensions and members of the back frame type curtain wall for office buildings. The insulation performance of the alternative case was compared with that of the base case by obtaining the heat loss and the resulting effective $U$-factor as well as the lowest indoor surface temperature and the resulting temperature difference ratio (TDR) through 
three-dimensional steady-state heat transfer simulation. In addition, mock-up tests were performed to compare the U-factors of the base case and alternative case. Furthermore, mock-ups were manufactured for testing U-factors of the base case and alternative case, and the improvements on insulation performance through application of TIF was verified. The main results of this study are as follows.

(1) The simulation results showed that the effective U-factor of the alternative case was $36 \%$ lower than that of the base case, indicating a significant reduction in heat loss by decreasing the thermal bridging effect. The lowest indoor surface temperature of the alternative case was $0.5^{\circ} \mathrm{C}$ higher than that of the base case, showing that the surface condensation risk was also reduced.

(2) In the mock-up test results, the U-factor of the alternative case was 33\% lower than that of the base case in a similar to the degree of reduction of the effective U-factor in the simulation results, confirming the large heat loss reduction effect of the alternative case.

(3) For the base case, both the effective U-factor by simulation and the U-factor by the mock-up test were much higher than the design U-factor according to the Design Standard, which does not consider the influence of the thermal bridge, indicating a significant increase in heat loss caused by the thermal bridge. For the alternative case, however, both were found to be similar to the design U-factor.

In this study, among the inorganic insulation materials widely used in the Korean insulation market, glass wool with high insulation performance was applied, and for further studies, high-performance insulation material, other than glass wool, that have fire resistance and insulation performance will be reviewed. Additionally, further research will be conducted to supplement the insulation performance and constructability of curtain wall systems that applied TIF by improving the insulation performance of primary and secondary connectors for fixing frames and exterior finish materials, applying such exterior materials as metal panels containing insulation besides the exiting metal sheet or stone, and introducing unit curtain wall construction methods in addition to the existing stick curtain wall construction method.

Author Contributions: Methodology, software, validation, and writing-original draft preparation, B.-H.C.; project administration, funding acquisition, writing-review and editing, and supervision, S.-Y.S. Both authors have read and agreed to the published version of the manuscript.

Funding: This work was supported by a Korea Institute of Energy Technology Evaluation and Planning (KETEP) grant funded by the Korean government (MOTIE) (grant number 20202020800360, Innovative Energy Remodeling Total Technologies for the Aging Public Buildings).

Institutional Review Board Statement: Not applicable.

Informed Consent Statement: Not applicable.

Data Availability Statement: Not applicable.

Acknowledgments: The authors are specially grateful to D.-I. Shin for providing the details of curtain wall systems applying TIF and making mock-ups.

Conflicts of Interest: The authors declare no conflict of interest.

\section{References}

1. Joint Ministries of Korean Government. Revision of the Basic Roadmap for Achieving the National Greenhouse Gas Reduction Target in 2030; Joint Ministries of Korean Government: Sejong, Korea, 2018.

2. Ministry of Land, Infrastructure and Transport. Press Release, Zero Energy Building, Beyond Buildings to Cities; Korean Ministry of Land, Infrastructure and Transport: Sejong, Korea, 2019.

3. Park, M.-J.; Song, J.-H.; Lim, J.-H.; Song, S.-Y. Analysis of needs for building envelope insulation regulations reflecting the thermal bridging effects through similar regulations review and case study. J. Archit. Inst. Korea Plan. Des. 2015, 31, 303-312. [CrossRef]

4. Ministry of Land, Infrastructure and Transport. Design Standard for Energy-Efficient Buildings; Notification No. 2017-881; Korean Ministry of Land, Infrastructure and Transport: Sejong, Korea, 2017. 
5. Song, J.-H.; Lim, J.-H.; Song, S.-Y. Evaluation of alternatives for reducing thermal bridges in metal panel curtain wall systems. Energy Build. 2016, 127, 138-158. [CrossRef]

6. Song, J.-H.; Park, M.-J.; Lim, J.-H.; Song, S.-Y. Energy, condensation risk and constructability evaluation of metal-exterior curtain wall panel systems for reducing heat loss through thermal bridges. J. Archit. Inst. Korea Plan. Des. 2015, 31, 283-293. [CrossRef]

7. Kim, S.-S.; Yim, H.-C. Evaluation of the Thermal Transmittance of Curtain walls according to EN 13947. J. Archit. Inst. Korea Plan. Des. 2012, 28, 401-408.

8. Song, J.-H.; Park, S.-H.; Park, M.-J.; Lim, J.-H.; Song, S.-Y. Influence of thermal bridges on the insulation performance of curtain wall panel systems. J. Asian Archit. Build. Eng. 2015, 14, 741-748. [CrossRef]

9. Brent, G.; Elizabeth, F.; Mehrangiz, Y.; Dariush, A. The significance of bolts in the thermal performance of curtain-wall frames for glazed facades. In Proceedings of the ASHRAE Winter Meeting, San Francisco, CA, USA, 17-21 January 1998.

10. Park, H.-Y.; Park, S.-J. A study on the thermal performance factors and effects of each part of curtain wall frame for development of curtain wall frame with thermal conductivity $1.0 \mathrm{~W} / \mathrm{m}^{2} \mathrm{~K}$ or less. J. Korean Inst. Archit. Sustain. Environ. Build. Syst. 2020, 14, 484-496.

11. Theodoros, G.T.; Aikaterini, G.T.; Karolos, J.K.; Dimitrios, K.B. Thermal bridging analysis on cladding systems for building facades. Energy Build. 2015, 109, 377-384.

12. Oh, J.-M.; Song, J.-H.; Lim, J.-H.; Song, S.-Y. Analysis of building energy savings potential for metal panel curtain wall building by deducing thermal bridges at joints between panels. Energy Procedia 2016, 96, 696-709. [CrossRef]

13. Shin, D.-I. Development of thermal breaker for the dry envelope and applied case. In Proceedings of the Annual Conference of AIK 2017, Gyeongju, Korea, 25-27 October 2017.

14. Song, J.-H.; Lee, D.-Y.; Shin, D.-I.; Jun, H.-D.; Park, C.-Y.; Kim, S.-K. Evaluation of building envelope Performance of a dry exterior insulation system using truss insulation frame. J. Archit. Inst. Korea Struct. Constr. 2019, 35, 153-164.

15. Song, J.-H.; Park, C.-Y.; Jeong, J.-W. Energy performance evaluation for exterior insulation system consisting of truss-form wire-frame mullion filled with glass wool. Energies 2020, 13, 4486. [CrossRef]

16. KS F 2278. Standard Test Method for Thermal Resistance for Windows and Doors; Korean Standard Association: Chungcheongbuk-do, Korea, 2017.

17. Ministry of Land, Infrastructure and Transport. Enforcement Decree of the Building Act; Notification No. 31270; Korean Ministry of Land, Infrastructure and Transport: Sejong, Korea, 2021.

18. ASHRAE Standard 90.1. Energy Standard for Buildings except Low-Rise Residential Buildings; American Society of Heating, Refrigerating and Air-Conditioning Engineers: New York, NY, USA, 2013.

19. ISO 10211: 2017. Thermal Bridges in Building Construction-Heat Flows and Surface Temperatures-Detailed Calculations; International Standard Organization: Geneva, Switzerland, 2017.

20. Physibel. TRISCO Manual of Version 14.0w; Physibel: Maldegem, Belgium, 2017; Available online: http://www.physibel.be (accessed on 7 May 2021).

21. Korea Energy Agency. Guide to Design Standard for Energy-Efficient Buildings; Korea Energy Agency: Ulsan, Korea, 2020.

22. ISO 10077-2: 2017. Thermal Performance of Window, Doors and Shutters-Calculation of Thermal Transmittance-Part2: Numerical Method for Frames; International Standard Organization: Geneva, Switzerland, 2017.

23. Ministry of Land, Infrastructure and Transport. Design Standard for Preventing Condensation in Apartment Buildings; Notification No. 2016-835; Korean Ministry of Land, Infrastructure and Transport: Sejong, Korea, 2016. 